\title{
TEATRO FEMINISTA: DA PESQUISA À SALA DE AULA ${ }^{123}$
}

\section{Autora: Profa. Dra. Maria Brígida de Miranda \\ Palavras-chave: teatro feminista; Vinegar Tom; montagem; Caryl Churchill}

Resumo: Em 2007 propus como texto a ser traduzido e discutido na pesquisa a peça teatral Vinegar Tom (1979), que assim como vários outros da autora inglesa Caryl Churchill, encontra-se dentro da categoria 'teatro feminista'. No semestre seguinte trabalhei esta peça nas disciplinas obrigatórias, Montagem Teatral I e II. Este artigo apresenta aspectos desta experiência, desde as leituras do texto no grupo de estudos; até a apresentação do espetáculo Vinegar Tom pela turma de Montagem I em novembro de 2007.

Em 2006, iniciei como parte de minha pesquisa, o grupo de estudos Teatro e Gênero. Meu objetivo foi o de criar um espaço, dentro da instituição universitária, onde questões acadêmicas, artísticas e de certa forma 'pessoais' relacionadas à 'identidade de gênero' pudessem ser levantas e discutidas. Supondo que o 'feminismo' ou a 'feminista' seria um 'tabu' mesmo entre as participantes do grupo de estudo, no sentido de que elas 'desconheciam' o assunto, o que os preveniria inicialmente de aproximações a assuntos correlatos, concluí que para se estudar o 'teatro feminista' seria necessário desconstruir certas noções historicamente carregadas, assim como os mecanismos que as perpetuam, sobre os movimentos feministas. Assim, perguntei em um dos encontros do grupo de estudo qual era a imagem que cada uma tinha do feminismo? As primeiras respostas foram noções como "mulheres que queimam sutiãs"; "mulheres que se acham superiores aos homens", "mulheres que querem ser superiores aos homens", as feministas seriam "mal-amadas" e "solteironas". Essas noções sobre 'feminismo', e a imagem das 'feministas' longe de serem irrelevantes me pareceram como um ponto de partida para discutir a visibilidade do trabalho de mulheres no teatro. As respostas refletiam as mesmas noções perpetuadas ao longo dos anos que constituem representações amplamente divulgadas da 'feminista' e do 'feminismo'. Talvez sejam estas mesmas noções que previnem, num primeiro momento, mulheres de quererem ser associadas a estas representações.

A partir de leituras introdutórias sobre a história do movimento feminista, e alguns conceitos trazidos pela teoria crítica feminista e estudos de gênero iniciamos debates sobre a desnaturalização

1 Pesquisa: Poéticas do Feminino e Masculino: A prática teatral na perspectiva das teorias de gênero

2 Universidade do Estado de Santa Catarina; Centro de Artes; Departamento de Artes Cênicas.

3 Uma versão ampliada deste artigo, com o título de Quem Tem Medo do Teatro Feminista? A experiência de Vinegar Tom da Pesquisa à Sala de Aula, foi apresentada e publicada no CDROM da I Jornada Latino-americana de Estudos Teatrais, de 3 a 4 de julho de 2008, na cidade de Blumenau, S.C.. 
da categoria 'mulher' e da noção de identidade fixa de gênero. Esse processo de 'desnaturalização' do 'feminino' e 'masculino' significou uma base para discutirmos o fazer artístico, especificamente a prática teatral. Como o teatro constrói representações de mulheres e homens a partir da repetição, já era uma das questões que Judith Butler em Gender Trouble (1999) usa como exemplo, ao propor a idéia de sexo como performativo. Como autores teatrais constroem personagens femininas e masculinas? Há alguma diferença na escrita de autoras e autores teatrais? As autoras são necessariamente feministas, ou escrevem necessariamente de forma diferenciada dos homens? Para entendermos estas questões fizemos leituras de peças teatrais escritas por mulheres, uma dessas peças foi Vinegar Tom (1976) uma peça declaradamente feminista.

\section{Mas o que é esse 'teatro feminista'?}

Da mesma maneira que ao lermos sobre o 'movimento feminista' percebemos que não se trata de um movimento único e homogêneo, mas com diferentes expressões de acordo com contextos políticosociais específicos; podemos começar por transformar o termo 'teatro feminista' em um plural. Pois é um termo que compreende uma grande variedade de práticas teatrais. Ao mesmo tempo podemos pensar nessas práticas numa primeira aproximação, como práticas de teatro político, mas de gênero específico. Ao discutir o teatro feminista no contexto inglês, Michelene Wandor (1986) explica que até 1968, a noção de 'diferença de gênero' ainda não era parte das discussões do teatro alternativo, incluindo o teatro político. Segundo Wandor os textos e os espetáculos mantinham uma perspectiva e abordagem masculina sobre problemas socias, econômicos e políticos. Foi, afirma Wandor, a "Revolução Teatral pós-1968" (1986:32) que trouxe assuntos relacionados a mulher e a orientação sexual para a agenda do teatro alternativo.

Autoras como Wandor, Sue-Ellen Case, Peggy Phelan e Lynda Hart entre outras traçaram o fenômeno do aparecimento de grupos de teatro feminista como um entrecruzamento entre teatro experimental e movimento feminista em países como EUA e Inglaterra nos anos 1960 e 1970. De uma maneira geral, o teatro feminista destas décadas é um teatro político de gênero específico, com conteúdo relacionado a experiências e problemáticas de mulheres em contextos culturais particulares. O texto Vinegar Tom pode ser visto como uma produção que reflete as experiências de um grupo específico de mulheres, no contexto da Inglaterra da década de 70. O encontro entre Churchill e atrizes do grupo de teatro Monstrous Regiment ajuda a ilustrar esse contexto histórico:

Caryl Churchill e membros do Monstrous Regiment encontraram-se por acaso em uma manifestação pró-aborto e rapidamente descobriram que elas estavam interessadas em encenar uma peça sobre bruxas, especialmente sobre as duras medidas que eram

DAPesquisa, Florianópolis, v.3 n.5, p.1184-1191, 2008. 
tomadas quando era descoberto que uma mulher era a chamada 'bruxa'. $<$ http://en.wikipedia.org/wiki/Vinegar_Tom_(play)>13/05/2008 [tradução da autora]

Essa citação além de contextualizar a presença de artistas, como ativistas no período efervescente do movimento feminista na Inglaterra, indica que uma das lutas do movimento feminista tornou-se um dos temas a serem explorados em Vinegar Tom. Assim como o aborto, outros temas são abordados na peça que Churchill escreve para o Monstrous Regiment, como a violência contra a mulher, tanto na esfera doméstica quanto pública; o estupro; a gravidez indesejada; a histeria; o casamento; o desejo sexual; o controle de natalidade e a menopausa. Todos estes assuntos que faziam parte problemática dos movimentos feministas da segunda onda, ganharam na escrita de Churchill uma historização. Churchill explica que quando foi convidada a escrever sobre a bruxaria ela tinha uma visão a partir da imagem das "fogueiras da inquisição, histeria e bacanais" que eram as representações mais freqüentes da 'caça as bruxas' em "filmes e ficção". No entanto, a partir da pesquisa que ela e o Monstrous Regiment realizaram nos arquivos de Essex sobre a 'caça as bruxas' elas perceberam como as acusações de bruxaria eram na verdade contra ofensas corriqueiras e banais como a morte de uma vaca ou a manteiga que não vem (CHURCHILL apud. REINELT 1990:156) [tradução da autora]. Para Churchill a bruxaria relacionavam-se à "pobreza, humilhação e preconceito e a auto-imagem das mulheres acusadas de bruxaria" (ibid.).

Assim, a necessidade de criar outros modelos de representação da mulher na arte, especificamente no teatro, foi uma das principais motivações para que nesses 'espaços de mulheres' e/ou 'espaços feministas' houvesse uma grande produção de textos teatrais. A escrita de Vinegar Tom pode ser tomada também como exemplo do que representou o teatro feminista nestas décadas. São textos que além de serem escritos por mulheres, têm também mulher como foco e costumam direcionar o discurso para outras mulheres. Parece apropriado pensar que, peças com estas características objetivam a conscientização de mulheres sobre os mecanismos de opressão e controle nas sociedades patriarcais.

Vale realçar que nas práticas de teatro feministas não há apenas a produção de textos mas uma principalmente há uma reformulação dos próprios meios de produção teatral. Torna-se comum a produção de textos a partir de improvisações e a partir de temas ou experiências pessoais. Vinegar Tom foi o primeiro texto que Churchill escreveu de forma colaborativa, e foi o segundo texto produzido pelo Monstrous Regiment usando essa estratégia de escrita <http://en.wikipedia.org/wiki/Vinegar_Tom_(play)>13/05/2008. De fato, uma das principais contribuições das práticas teatrais feministas é o desenvolvimento de estratégias colaborativas e 
coletivas para escrita de peças. Alison Oddey (1998) e Elaine Aston (1999) explicam como o teatro feito por mulheres e o teatro feminista desenvolveram inúmeras estratégias para a criação dos próprios textos e espetáculos. Muitos desses novos textos tinham estruturas que desconstruiam narrativas tradicionais; e quebravam os limites entre teatro 'de texto' e o teatro físico, o teatro visual e o circo.

Peta Tait, ao analizar as práticas teatrais feitas por mulheres na Autrália, observa que estas prática "ampliam o espectro das formas teatrais existentes" (2:1994) [tradução da autora]. Como afirma Tait a prática teatral feminista significa uma "construção de diferentes realidades teatrais"(2:1994)[tradução da autora]. Assim a relevância de se estudar 'teatros feministas' nas universidades é a de que essas práticas significaram uma transformação da prática teatral de forma mais geral, tanto no conteúdo e estéticas da peças teatrais e espetáculos como também nas estruturas de criação e trabalho.

\section{Vinegar Tom na Graduação}

Como parte da pesquisa pedi a uma das integrantes do grupo de estudos, a bolsista Cláudia Mussi, que fizesse uma tradução de Vinegar Tom. Em poucas semanas, já com a tradução na mão fizemos uma leitura dramática da peça de Churchill no grupo de estudos. Discutimos também as possibilidades de trabalho com este texto na graduação e após várias idéias e sugestões das participantes do grupo, resolvi levar esse texto como proposta para as disciplinas obrigatórias do curso de Artes Cênicas do Centro de Artes da UDESC, Montagem Teatral I e II, que ministraria respectivamente, em $2 / 2007$ e 1/2008. Além do conteúdo e formato feminista, a escolha do texto Vinegar Tom me pareceu adequada para o trabalho em sala de aula, considerando todas as limitações que o/a professor/a e alunos/as estão submetidos quando no contexto específico de sala de aula. A primeira questão era a de ter necessariamente que adequar o número de atores/atrizes ao número de papéis disponíveis de forma a dar oportunidades iguais a todos de atuarem. O texto tem 14 (quatorze) personagens mais a 'banda'. São 7 (sete) personagens femininos e 7 (sete) masculinos, sendo que 2 (dois) dos papéis masculinos: os inquisidores Kramer e Sprenger, segundo sugestão da autora em nota de rodapé, devem ser feitos por mulheres. Considerando o número maior de mulheres cursando artes, e fazendo uma estimativa do número de alunos cursando a disciplina naquele semestre a divisão de papéis por gênero seria possível necessitando apenas com pequenos ajustes (isso poderia ser feito, e foi feito com duas atrizes fazendo um mesmo personagem Beth (alternando os dias de apresentação). Dessa maneira conseguiríamos dar boas oportunidades de atuação para tanto os alunos quanto as alunas. A outra questão era relacionada às ausências dos 
atores, nas normas da universidade o/a aluno/a pode ter até $25 \%$ de faltas, isso significaria que dificilmente eu teria toda a turma presente para cenas que envolvessem muitos personagens. Nesse sentido a estrutura da peça em episódios favorecia o ensaio em pequenos grupos de dois a três atores. Esta estrutura me possibilitaria uma grande flexibilidade para ensaiar as cenas de acordo com os/as alunas/os presentes ao mesmo tempo em que manteria os direitos destes/as a faltas.

Cientes da escolha de Vinegar Tom e de seu conteúdo e formato feminista, dezoito estudantes matricularam-se em minha turma, sabendo que sob minha direção, executariam dois exercícios específicos da prática teatral: o trabalho de ator/atriz e o trabalho de realização do espetáculo. Em agosto de 2007 a turma, pela primeira vez, fez uma leitura dramática de Vinegar Tom. Durante esse mês repetimos esse procedimento, e essas leituras funcionaram em dois âmbitos: como momento dos/as alunos/as conhecerem o texto completo; e momento de experimentarem a interpretação de diferentes personagens. Deixei claro que as leituras dramáticas significavam também esse momento de definição do elenco. Durante e após a leitura, pedi que fizessem desenhos/escritas de imagens sugeridas pela leitura. Essa foi uma estratégia para acessar o que cada um achava do texto, dos personagens, de como gostaria de ver o elenco formado (sem que essas opiniões desencadeassem crises na turma). A decisão seria feita por mim considerando tanto as sugestões que eles/elas deram por escrito, tanto sobre o próprio papel quanto o dos/as colegas; quanto a minha concepção do espetáculo.

Essa concepção do espetáculo precisaria ter uma lógica de representação que realçasse uma abordagem feminista. Buscando uma lógica de narrativa visual o corpo dos atores/atrizes já estabeleceria a representação da fome e marginalidade vivida pelas mulheres solitárias. Assim, decidi que atrizes magras fariam os papéis das mulheres sozinhas, que vivessem a margem da sociedade e sem homens que as protegessem. Mulheres mais encorpadas interpretariam as mulheres casadas, ou acompanhadas. Dessa maneira a representação seria uma forma de relativizar os padrões de beleza contemporâneos que estabelecem o corpo magro como o belo e desejável. Por outro lado, a banda de rock seria a representação da mulher contemporânea, e deveria ser formada apenas por alunas. Isso determinou outro aspecto da distribuição de papéis, a escolha de atrizes com habilidades musicais. Devido à limitação de tempo de ensaio e montagem, a banda precisaria ser composta preferencialmente por mulheres que já cantassem ou tocassem algum instrumento. Interessante observar que, a maioria das minhas escolhas coincidiram com, ou refletiram as escolhas que os/as alunos/as já haviam feito por escrito.

A importância da distribuição dos papéis primeiro no mês de aula significou a definição de tarefas 
para cada aluno/a enquanto ator/atriz. Com o personagem definido o/a aluno/a poderia se concentrar na leitura de suas cenas e na construção do personagem a partir do entendimento texto, e das tentativas de construção da partitura de ações físicas que o personagem precisaria realizar na cena. Enquanto eu trabalhava na construção de uma determinada cena com um grupo de atores, a mestranda Paula Rojas, como assistente de direção, trabalhava com outro grupo de atores na leitura do texto e na identificação e construção de verbos de ação, de intenções que moveriam os personagens na cena. Assim, os personagens foram sendo construídos a partir de leituras do texto e durante o processo de construção da cena. No final do segundo mês o espetáculo já tinha 8 (oito) de 21 (vinte e uma) cenas esboçadas.

É necessário considerar que este formato e velocidade de produção refletiam mais as limitações de tempo enquanto produção teatral em uma disciplina do que quaisquer das estratégias de criação e ensaio típicas das práticas feministas. Por outro lado, havia uma tentativa de divisão de tarefas que envolvia a todos os participantes em equipes de trabalho, muitas destas equipes desenvolvendo trabalhos criativos como figurinos, luz, cenário e objetos de cena; além da banda que preservava um espaço privilegiado de criação. A equipe de preparação corporal -- que incluía a prática de Tai-ChiChuan conduzida por Rojas; e envolvia os acadêmicos Elisza Schmidt na condução de exercícios de Yoga e Fabiano Lodi e Letícia Martins na aplicação dos exercícios de View-Points - significava também um espaço onde a liderança era passada da professora/diretora para outros membros da equipe. Essa circulação de papéis de liderança é uma característica de vários grupos de teatro feministas, mas não exclusivamente, e está relacionada ao exercício de empoderamento e agência.

Ao final do semestre de Montagem Teatral I, o espetáculo completo já estava estruturado. Vinegar Tom foi apresentado com suas 21 cenas tipo 'episódios', interpretadas por 12 atores. As cenas eram intercaladas pelas canções como sugerido no texto de Churchill. As 7 (sete) canções originais em inglês foram traduzidas e adaptadas totalizando 8 músicas (letras e melodias) criadas e tocadas ao vivo pela banda composta por quatro alunas $^{4}$ da disciplina e uma aluna ${ }^{5}$ do curso de Música do CEART que formaram Aquela Banda da Montagem. O espetáculo tentou manter pelo figurino e objetos de cena o aspecto de peça histórica; ao passo que a banda 'comentava' e 'criticava' a situação vivida pelos personagens na cena, estabelecendo para a platéia um paralelo com assuntos contemporâneos. Mantendo assim, a proposta do texto de Churchill e da primeira encenação do Monstrous Regiment. A disposição da banda em relação as cenas no espaço teatral, Espaço 2,

4 Cláudia Mussi; Luana Garcia; Lívia Sudare e Fernanda Macedo.

5 Renata Swoboda, que realizou também juntamente com o aluno Felipe Queriquelle as paisagens sonoras da peça. A orientação deste trabalho foi do Prof. Mestre Frederico Macedo, do Departamento de Música (CEART/UDESC).

DAPesquisa, Florianópolis, v.3 n.5, p.1184-1191, 2008. 
realçava nessas apresentações a posição privilegiada da banda (mulheres atuais) em relação a cena (história das mulheres). A banda tocava no mezanino atrás e superior ao espaço da cena. Deste espaço a banda poderia acompanhar a cena; e ser vista pela platéia, mas também ficava claro para a platéia que a banda também poderia observar os espectadores. Jill Dolan (1991) mostra como uma das preocupações das teorias feministas dizem respeito ao 'olhar' e a posição privilegiada do espectador. Nesse sentido o poder da banda de rock em 'olhar de volta' para a platéia pode sugerir que a relação de poder entre o espectador/a e o/a ator/atriz torna-se mais equilibrada. Este 'olhar de volta' para a platéia é explorado também nas cenas de duas 'mulheres velhas' a personagens Goody ${ }^{6}$, a caçadora de bruxas; e Joan Noahs ${ }^{7}$ uma viúva que é acusada de bruxaria pela vizinhança. Assim, o espetáculo tenta criar momentos onde a teoria feminista encontra espaços de aplicação.

É preciso considerar que essas relações entre prática e teoria não são construídas necessariamente ao longo do processo de ensaio e aulas. Enquanto algumas reflexões são feitas em debates em sala de aula sobre o significado da cena, ou a relação entre cena e espaço teatral; outras reflexões acontecem a partir de leituras individuais ou de debates no grupo de estudos Teatro e Gênero. O que me parece ser uma realização importante com a produção de Vinegar Tom no curso de Artes Cênicas da UDESC é que reflexões sobre o espetáculo Vinegar Tom -- com sua estética e conteúdo de teatro feminista -- podem continuar fluindo por bastante tempo, principalmente por aqueles/as que vivenciaram o processo da Montagem Teatral I, seja enquanto espectadores; como atores/atrizes ou como professores/as e bolsistas de outros departamentos que colaboraram nesse processo.

\section{REFERÊNCIAS:}

ASTON, Elaine. Feminist Theatre Practice: A Handbook. London: Routledge, 1999.

BUTLER, Judith. Gender Trouble: Feminism and the Subversion of Identity. New York: Routledge, 1999.

CASE, Sue-Ellen, ed. Performing Feminisms: Feminist Critical Theory and Theatre. Baltimore: The Johns Hopkins University Press, 1990.

CHURCHILL, Caryl. Vinegar Tom. Trad. Cláudia Mussi. (Texto não publicado, tradução realizada para a pesquisa Poéticas do Feminino e Masculino: A prática teatral na perspectiva das teorias de gênero).

DOLAN, Jill. The Feminist Spectator as Critic. 1988. Ann Arbor, Mich.: University of Michigan Press, 1991.

HART, Lynda, and Peggy Phelan, eds. Acting Out: Feminist Performances. Ann Arbor: The University of Michigan Press, 1993.

MICHAELIS: Moderno Dicionário da Língua Portuguesa.

São Paulo: Companhia Melhoramentos. 1998.

ODDEY, Alison. "Devising (Women's) Theatre as Meeting the Needs of Changing Times." The Routledge Reader in Gender and Performance. Eds. Lizbeth Goodman and Jane de Gay.

6 Interpretada por Mariana Candido. Este papel foi interpretado pela Profa. Fátima Lima no espetáculo apresentado no Festival de Teatro Isnard Azevedo em 17 de abril de 2008.

7 Interpretada por Maria Fernanda Jacobo. 
London: Routledge, 1998. 191-24.

REINELT, Janelle. "Beyond Brecht: Britain's New Feminist Drama." Performing Feminisms: Feminist Critical Theory and Theatre. Ed. Sue-Ellen Case. Baltimore: The Johns Hopkins University Press, 1990. 150-9.

TAIT, Peta. Converging Realities: Feminism in Australian Theatre. Sydney: Currency Press, 1994.

WANDOR, Michelene. Carry on, Understudies: Theatre and Sexual Politics. London: Routledge \& Kegan Paul, 1986.

<http://en.wikipedia.org/wiki/Vinegar_Tom_(play)>13/05/2008. 